\title{
A PRESENÇA DOS ADOLESCENTES NA EJA: IMPLICAÇÕES POLÍTICAS E PEDAGÓGICAS
}

Orientando: Juliana Bicalho de Carvalho Barrios

Orientadora: Marleide Rodrigues da Silva Perrude

O presente trabalho tem como objetivo discutir sobre o fenômeno da juvenilização da Educação de Jovens e Adultos (EJA). Utilizando-se da pesquisa qualitativa, realizamos um estudo bibliográfico e buscamos responder as seguintes questões: $O$ que leva o adolescente e o jovem a frequentar a EJA? Quais as características do público jovem e adolescente que frequenta a modalidade? Para tanto, estudamos os documentos norteadores da EJA, tais como: a Constituição Federal (BRASIL, 1988), a LDB Lei 939496 (BRASIL, 1996) e as Diretrizes Nacionais para a Educação de Jovens e Adultos (BRASIL, 2000). Discutimos a EJA no cenário brasileiro, a crescente presença de adolescentes e as implicações políticas e pedagógicas na presente modalidade. Nesse sentido, concluímos que é necessário repensar a educação no que tange os ensinos fundamental e médio da escola regular, bem como, repensar a EJA a partir da sua configuração e novo perfil de educando.

Políticas Públicas. Educação de Jovens e Adultos. Juvenilização.

\section{INTRODUÇÃO}

A educação de Jovens e adultos (EJA) é uma das modalidades de ensino da educação básica no Brasil. Essa modalidade é destinada a jovens e adultos que, por algum motivo, não concluíram os estudos nas séries do ensino fundamental ou não chegaram a iniciar o seu processo de escolarização.

A lei de Diretrizes e Bases da Educação Nacional (LDBEN), n. 9394/96, prescreve no artigo 37 que "A educação de Jovens e Adultos será destinada àqueles que não tiveram acesso ou continuidade de estudos no ensino fundamental e médio na idade própria”. O documento de Diretrizes Curriculares da Educação de Jovens e Adultos no Brasil, estabelecido na Resolução CNE/CEB n ${ }^{\circ}$, de 05/07/2000, aponta que uma das funções sociais da EJA é desempenhar com os alunos a sua formação humana e o acesso à cultura, tendo como um dos objetivos aprimorar a consciência crítica, atitudes éticas e compromisso político desses alunos, para que, então, eles possam desenvolver a sua autonomia intelectual.

A educação pública no Brasil voltada para os jovens e adultos oferece a esses educandos a oportunidade e o direito de elevar o seu nível de escolaridade, por meio de diversos conhecimentos que podem ser aplicados na sua vida cotidiana e, futuramente, proporcionar uma melhoria na qualidade de vida.

De acordo com as Diretrizes Curriculares Nacionais de EJA,

A nova concepção da EJA significa, pois, algo mais do que uma norma programática ou um desejo piedoso. A sua forma de inserção 


\section{SEMINÁRIO DE PESQUISA EM CIÊNCIAS HUMANAS - SEPECH \\ Humanidades, Estado e desafios didático-científicos \\ Londrina, 27 a 29 de julho de 2016}

no corpo legal indica um caminho a seguir. A EJA é educação permanente, embora enfrente os desafios de uma situação sócioeducacional arcaica no que diz respeito ao acesso próprio, universal e adequado às crianças em idade escolar (BRASIL, 2000, p. 66).

Para falar da gênese da Educação de jovens e adultos no Brasil, precisamos voltar o nosso olhar para o Brasil Colônia, situando a presença de religiosos que exerciam uma função educativa missionária com os índios e, posteriormente, com os escravos. A educação tratada na época tinha um caráter religioso, porém, também era transmitido aos alunos normas de comportamento e estudos sobre o funcionamento da economia colonial. Mais tarde, destinado aos colonizadores e seus filhos, surge a escola de humanidades.

Em 1759, a expulsão dos jesuítas acarretou uma desorganização no sistema do ensino no Brasil e só foi ouvido falar novamente sobre a Educação de Jovens e Adultos nos tempos do Império.

A primeira constituição brasileira, criada em 1824, firmou a garantia de uma instrução primária e gratuita para todos os cidadãos, sendo assim, crianças, jovens e adultos, tinham direito a estudar. $\mathrm{O}$ direito à educação pública e de qualidade, que nasceu com a norma constitucional de 1924, se firmou apenas como intenção legal.

A implementação de uma escola que ofereça educação básica e de qualidade para todos, vem avançando lentamente na história do Brasil e a afirmação da mesma, como direito, ainda é um grande desafio. A partir disso, a EJA veio crescendo e criando o seu espaço de forma discreta e descontinua, por meio de alguns acontecimentos políticos. Alguns deles foram essenciais para sua consolidação como categoria de ensino no Brasil, entre eles, a criação do Fundo Nacional do Ensino Primário (FNEP), criação do Instituto Nacional de Estudos e Pesquisas (INEP) e o lançamento da Campanha de Adolescente e Adultos (CEAA), iniciativas da UNESCO e demais movimentos internacionais, pesquisas e ações de Paulo Freire e demais teóricos, Movimento Brasileiro de Alfabetização (MOBRAL), Estatuto da Fundação Nacional para Educação de Jovens e Adultos (EDUCAR) aprovado pelo decreto $n^{\circ}$ 92.374, o Ensino Supletivo firmado pela Lei $n^{0}$ 5.692/71, a Constituição de 1988 que garante a oferta do ensino fundamental obrigatório e gratuito para aqueles que não tiveram acesso na idade apropriada, a Lei de Diretrizes e Bases da Educação Nacional (LDB 9394/96), a criação da Secretaria Extraordinária de Erradicação do Analfabetismo, o PROJOVEM, em 10 de Maio do ano 2000 a criação da Diretriz Curricular Nacional para a Educação de Jovens e Adultos - DCN, as Confinteas e demais acontecimentos.

Entretanto, não devemos esquecer que a EJA no Brasil foi marcada pela ausência de políticas públicas, ou seja, as políticas direcionadas à modalidade foram caracterizadas e, em alguns espaços ainda permanecem, balizadas pelo caráter assistencial. Apesar dos avanços, pouco se tem feito para uma melhoria significativa e desenvolvimento da Educação de Jovens e Adultos no Brasil. Permanece em nosso país a ideia de que a EJA tem um caráter solidário ou de política compensatória, o que não é correto afirmar. Olhando as diversas necessidades que ainda não foram atendidas e, principalmente, tendo em vista o dado de que em 2013, o Brasil registrou 13 milhões de analfabetos com 15 anos ou mais (IBGE, 2013), entendemos que não houve a melhoria necessária para a modalidade. Avançou-se, porém, não o quanto deveria. Tem-se a ideia equivocada de que a oferta da educação para jovens e adultos é "favor do estado" pelo 


\section{SEMINÁRIO DE PESQUISA EM CIÊNCIAS HUMANAS - SEPECH \\ Humanidades, Estado e desafios didático-científicos \\ Londrina, 27 a 29 de julho de 2016}

motivo de a modalidade atender, em sua maioria, pessoas excluídas da sociedade. Tal realidade revela, como afirma a própria diretriz, que a EJA ainda "representa uma dívida social não reparada para com os que não tiveram acesso a e nem domínio da escrita e leitura." [...] (BRASIL, 2000, p.32)

Devido à banalização da Educação, evidenciada pelo seu percurso histórico no Brasil, os alunos ingressantes na EJA são, em sua maioria, trabalhadores, com histórias de vida marcadas pela exclusão e oriundos de camadas populares. Concordando com essa questão, Giovanetti (2005) escreve que,

A vivência do processo de exclusão social, fruto do agravamento da desigualdade social que expressa na falta de moradia, nãoatendimento à saúde, falta de oportunidades de trabalho e, inclusive, não-acesso à educação, é uma experiência que deixa profundas marcas nos seres humanos. São jovens e adultos que vão construindo, ao longo de suas vidas, uma auto-imagem marcada pela negatividade (GIOVANETTI, 2005, p. 245).

Ainda sobre a marca identitária dos educandos da presente modalidade, Farias (2012) afirma que,

Partimos do pressuposto que a subalternidade da EJA nas ações do Estado coaduna com a história do lugar social reservado às classes populares na oferta educacional. Isto é caracterizar os(as) educandos(as) da EJA pelo recorte de classe, considerando as particularidades e especificidades que identificam as pessoas jovens, adultas e idosas, mas imprimindo a generalização analítica das categorias gramscinianas ao propor os termos 'classes subalternas ou grupos subalternos'. O emprego da categoria subalterna é apropriado, pois designa na sociedade capitalista o tipo de relação entre as classes, portanto a relação de subordinação dos interesses dos integrantes das classes subalternas aos interesses da classe dominante. No âmbito da organização societária, o conceito estabelece uma relação dialética com o Estado, a sociedade civil e a hegemonia (FARIAS, 2012, p.02).

Deste modo, entendemos que ainda há muito o que avançar no que tange à política de EJA no Brasil. É necessário, assim como Rummert (2008) afirma, que a permanência no ensino fundamental e o acesso ao Ensino Médio não sejam mais privilégios, mas sim, garantidos à todos. Só assim, asseguraremos que os nossos alunos, por meio da educação, estarão devidamente instruídos e aptos para inserirem-se no ensino superior e no mercado de trabalho e, deste modo, garantiremos que eles não tomem outros caminhos indesejáveis.

as políticas de governo atualmente implementadas no âmbito da educação de jovens e adultos trabalhadores, no Brasil, estão fundadas em estratégias de construção e manutenção da hegemonia que perpetuam, sob diferentes roupagens, as relações fortemente assimétricas de poder, bem como os processos de concentração de riqueza e renda que marcam o País. Tais políticas, portanto, se apresentam como instrumentos de manutenção da ordem instituída e não objetivam a formação integral, concorrendo, como já demonstrado 


\section{SEMINÁRIO DE PESQUISA EM CIÊNCIAS HUMANAS - SEPECH \\ Humanidades, Estado e desafios didático-científicos \\ Londrina, 27 a 29 de julho de 2016}

em outros trabalhos (RUMMERT, 2004, 2005, 2006, 2007a e 2007b), para a histórica dualidade estrutural de nossa sociedade (RUMMERT, 2008, p.176).

Contudo, enfatizamos a crítica à política de governo que, ainda nos tempos atuais, visa os interesses hegemônicos, não se diferenciando das demais políticas já implementadas e citadas aqui. É preciso que se pense e, principalmente, se aplique uma política que objetive a formação integral do ser humano para que a citada "dualidade estrutural" seja extinguida. Para tanto, é necessário que se busque uma educação libertadora; que os alunos da EJA sejam ensinados a pensar, e não ensinados a obedecer, como as escolas vêm fazendo nos tempos atuais; que eles se vejam como agentes transformadores da sua própria realidade e sujeitos ativos desse processo. Ainda sobre essa questão, Rummert salienta que,

A emancipação humana pressupõe a superação dos múltiplos obstáculos impostos à vida individual e coletiva pela alienação do trabalho no modo de produção capitalista. Como construção comum a todos, a emancipação humana se caracteriza pela imposição do controle do homem coletivo sobre as condições sociais de produção da existência. (RUMMERT, 2008, p. 188)

Nesse sentido, entendemos que a escola e a educação possuem uma missão fundamental no processo de manutenção da hegemonia e da emancipação humana. A educação é, sem dúvidas, o maior agente transformador da realidade instituída.

\section{JUVENILIZAÇÃO DA EJA}

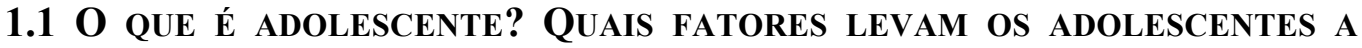 ESTAREM NA EJA?}

Uma das maiores preocupações dos responsáveis e envolvidos na Educação de Jovens e Adultos é a atual composição das turmas. As classes de EJA, há pouco tempo atrás, eram quase que, hegemonicamente, de adultos e idosos, que procuravam a modalidade buscando, principalmente, a alfabetização.

Entretanto, atualmente, a EJA está vivenciando um processo de transformação. O adolescente está cada dia mais presente na modalidade e, com isso, a EJA está criando uma nova configuração de suas turmas. Com o abandono dos ensinos fundamental e médio das escolas regulares e inserção na presente modalidade, está acontecendo o que alguns estudiosos chamam de "rejuvenescimento da EJA", pois, o crescimento do número da presença do público mais jovem está cada dia mais evidente.

Sobre este fenômeno, Brunel (2004) escreve que

o rejuvenescimento da população que frequenta a EJA é um fato que vem progressivamente ocupando a atenção de educadores $\mathrm{e}$ pesquisadores na área da educação. $\mathrm{O}$ número de jovens $\mathrm{e}$ adolescentes nesta modalidade de ensino cresce a cada ano, 


\section{SEMINÁRIO DE PESQUISA EM CIÊNCIAS HUMANAS - SEPECH \\ Humanidades, Estado e desafios didático-científicos \\ Londrina, 27 a 29 de julho de 2016}

modificando o cotidiano escolar e as relações que se estabelecem entre os sujeitos que ocupam este espaço (BRUNEL, 2004, p.9).

Segundo dados do Instituto Brasileiro de Geografia e Estatística (IBGE), no Brasil, em 2013, foram registrados 13 milhões de analfabetos com 15 anos ou mais, sendo analfabeto o indivíduo que não consegue ler e escrever um bilhete simples. Esse dado indica mudança da estrutura econômica, política, social e cultural da sociedade brasileira.

Sobre os sujeitos com idade inferior a 30 anos, o IBGE aponta que a taxa de analfabetismo ficou abaixo de $3 \%$ em 2013. Por sua vez, a faixa de idade entre 40 a 59 anos, a taxa é de 9,2\%. Já a faixa de idade dos idosos analfabetos, tendo eles 60 anos ou mais, alcançou 23,9\%. O IBGE também coloca que a taxa de analfabetismo vem decaindo entre os jovens de até 25 anos. A partir da faixa etária de 40 anos, a taxa é alta, sendo o principal motivo a falta de acesso à educação. (IBGE, 2010). O debate da presença de alunos cada vez mais jovens na EJA vem provocar esse dado, uma vez que o índice de "reprovação e de abandono no Ensino Médio são, respectivamente, 13,1\% e de 14,3\%" (BRASIL, 2013, p. 149), evidenciando um número elevado de educandos que abandonam a escola nessa etapa de escolarização. Do mesmo modo, o UNICEF cita um dado no documento que aponta os 10 desafios para o Ensino Médio evidenciando que o número de adolescentes de 15 e 17 anos que completaram o ensino médio é de 448.514 milhões. O dado é alarmante, uma vez que corresponde a apenas 13,2\% em relação ao total de adolescentes que deveriam ter concluído essa etapa. (UNICEF, 2014, p.30).

Diante do exposto é possível afirmar que, de fato, estamos caminhando para a erradicação do analfabetismo, mas, em contrapartida, não estamos caminhando para o desenvolvimento de uma sociedade escolarizada. Nesse sentido, o adolescente na EJA vem ganhando destaque nas discussões da educação, uma vez que a presença desse adolescente altera completamente o cotidiano escolar na modalidade e, principalmente, questiona o atual modelo educacional brasileiro.

\subsection{O Adolescente na EduCaÇão de Jovens e Adultos}

O ser humano passa por inúmeras transformações em todas as fases da vida, sendo elas, influenciadas por diversos fatores. É sob essa lógica que acontece o desenvolvimento humano. Nesse sentido, Oliveira afirma que

As características da espécie e das várias fases de desenvolvimento onto-genético serão interpretadas de acordo com as visões de mundo e as formas de significação próprias de cada cultura. A puberdade, por exemplo, conjunto de transformações fisiológicas ligadas à maturação sexual do indivíduo, é interpretada e tratada de formas diversas em diferentes culturas. Pode levar ao casamento e procriação imediatos, ao isolamento do jovem em casas separadas para pessoas dos sexos masculino e feminino, à criação de categorias socialmente reconhecidas denominadas 'adolescentes' e 'pré-adolescentes', a práticas de inicia-ção ligadas à religião, etc. Do mesmo modo, outros fenômenos do desenvolvimento, originalmente provenientes de 


\section{SEMINÁRIO DE PESQUISA EM CIÊNCIAS HUMANAS - SEPECH \\ Humanidades, Estado e desafios didático-científicos \\ Londrina, 27 a 29 de julho de 2016}

características da espécie ou das fases de desenvolvimento individual (por exemplo, o treino para controle das funções excretoras, a aquisição da linguagem, a velhice), recebem significação e tratamento peculiar dentro de cada cultura (OLIVEIRA, 1997, p.55).

Sob a ótica de Oliveira (1997) entendemos que a interpretação do desenvolvimento do ser humano acontece diante das visões de mundo e a significação da cultura de cada um. Deste modo, o tempo que marca as fases das etapas de desenvolvimento, como a puberdade, por exemplo, podem variar em determinadas culturas.

O termo "adolescência" tem sua origem no latim nas palavras $a d=$ "para" e olescere = "crescer". Portanto, o termo adolescência significa "crescer para" (PEREIRA, 2014). Com base na definição terminológica, entendemos que o sujeito que vive o período da adolescência é alguém que está vivenciando um período de crescimento para tornar-se algo, no caso, um adulto.

Entende-se que o sujeito adolescente está vivenciando um processo de estruturação e amadurecimento e, devido a isso, não está preparado para a vida e, sobretudo, para assumir determinadas responsabilidades. Justificável por estar em constante formação, o sujeito precisa experimentar, testar e tentar para entender as suas capacidades e limites. É possível, devido à toda a sua especificidade comparar o momento da adolescência a um limbo, ou seja, um momento de completa indefinição.

Entendemos também que o adolescente é um sujeito que está negligenciado e esquecido. O sujeito em questão não é mais criança, mas, também, não pode ser considerado adulto, pois, ainda não amadureceu e, passará por uma série de transformações que ocasionará em sua estruturação enquanto adulto. Contudo, a adolescência caracteriza-se por uma fase de intensos conflitos, sobretudo, por ser uma fase de muitas mudanças e o sujeito, devido à sua indefinição, não sabe exatamente o que ele é, pois, traz em sua personalidade e comportamento, ora características de uma criança, ora características de um adulto. Deste modo, o conceito de adolescência vai além de transformações físicas, pois, engloba os inúmeros processos de mudança e adaptação psicológica e social.

A Lei $\mathrm{n}^{\circ}$ 8.069, mais conhecida como Estatuto o da Criança e do Adolescente (ECA) define em seu artigo $2^{\circ}$ que adolescentes são os sujeitos que possuem idade entre 12 e 18 anos de idade. Sendo anterior à essa fase, as crianças, cujo os sujeitos possuem idades com até 12 anos incompletos

O presente cenário da EJA, com a presença massiva dos adolescentes na modalidade, tem chamado a atenção dos especialistas que estudam a educação. Segundo a Revista Escola "a presença de adolescentes na Educação de Jovens e Adultos (EJA) no Ensino Fundamental é preocupante: quase 20\% dos matriculados têm de 15 a 17 anos. $\mathrm{O}$ número de alunos dessa faixa etária na modalidade não tem sofrido grandes variações nos últimos anos, apesar da queda no total de matrículas $(28,6 \%)$. Dados da Ação Educativa com base nos Censos Escolares indicam que, em 2004, eram 558 mil estudantes e, em 2010, 565 mil.” (FERNANDES, 2011). 


\section{SEMINÁRIO DE PESQUISA EM CIÊNCIAS HUMANAS - SEPECH \\ Humanidades, Estado e desafios didático-científicos \\ Londrina, 27 a 29 de julho de 2016}

\subsection{OS FATORES}

Determinados fatores levam o aluno adolescente a buscar matrícula na modalidade de EJA. Os alunos adolescentes exercem presença marcante na modalidade, apesar de terem sido excluídos das discussões que situam tal modalidade no cenário brasileiro. Estudos revelam a diversidade ou a heterogeneidade das salas de EJA. Questão pertinente, uma vez que, se um adolescente está frequentando a EJA, é um sujeito marcado pelo abandono ou pela negação do direito ao acesso à escola.

Vale ressaltar que, quando um adolescente chega na EJA, ele está desanimado, desmotivado e traumatizado com a escola e com o histórico de repetências de um, dois, três anos ou mais. Além disso, sentem-se perdidos no contexto atual, principalmente com as exigências da escolarização para a inserção no mercado de trabalho.

Segundo Ribeiro,

Perceber esses jovens do ponto de vista da EJA revela uma condição marcada por profundas desigualdades sociais. Na escola de EJA estão os jovens reais, os jovens os quais o sistema educacional tem dado as costas. Percebê-los significa a possibilidade de dar visibilidade a esse expressivo grupo que tem direito à educação e contribuir para a busca de resposta a uma realidade cada vez mais aguda e representativa de problemas que habitam o sistema educacional brasileiro como um todo (RIBEIRO, 2004, p.45).

Entre os diversos fatores que levam um aluno a abandonar o sistema regular de ensino, podemos inferir a partir de observações em salas de EJA e apoiando a discussão nos autores que estudam a presença do adolescente na modalidade, que os principais e mais comuns fatores são: a evasão; a questão de eles não se encaixarem no sistema regular de ensino; o suposto "problema" da indisciplina; o desinteresse nos estudos; a necessidade do jovem inserir-se cada vez mais precocemente no mercado de trabalho; o crime e as drogas; ser oriundo de regiões periféricas ou zona rural que, diferentemente da zona urbana, são regiões de difícil acesso à escolarização e a criminalização da juventude.

Por ora, não será possível nos aprofundarmos na discussão acerca dos fatores que levam o adolescente a buscar a EJA. Entretanto, a partir desses fatores, nos debruçaremos no o que a presença desse educando acarreta na presente modalidade.

\section{CONSIDERAÇÕES FINAIS}

Ao concluir essa discussão, entendemos que a questão da juvenilização da EJA é um fenômeno em que a dimensão não atinge somente tal modalidade, ela perpassa o campo da EJA e atinge a educação como um todo. A presença desses adolescentes na EJA revela, sobretudo, o quanto o fracasso escolar está presente nas escolas atuais e se reproduzindo cada vez mais rápido, pois, o número de educandos mais jovens na EJA está crescendo a cada ano.

Com base nos debates realizados nesta pesquisa e focando no aspecto da evasão escolar e indisciplina, sendo o primeiro um dos fatores mais comuns quando falamos do 


\section{SEMINÁRIO DE PESQUISA EM CIÊNCIAS HUMANAS - SEPECH \\ Humanidades, Estado e desafios didático-científicos \\ Londrina, 27 a 29 de julho de 2016}

abandono da escola pelos adolescentes, e o segundo, uma característica dos mesmos, entendemos que, somente quando o aluno abandona os ensinos fundamental e médio regular, ele é "notado", pois, é neste momento, que ele se encontra fora do "contexto" e, consegue aparecer de forma mais evidente, por não ser a maioria. E, trazendo consigo as suas características de adolescente, é visto equivocadamente como um problema. Ou seja, aquele que, por vezes foi chamado equivocadamente de problema no ensino fundamental regular, pelos motivos de ser muito mais velho que os demais educandos; apresentar um comportamento que foge aos moldes de disciplinamento demasiado da escola e, sob a ótica da equipe pedagógica, não se interessar pelos estudos; volta a ser visto como problema na EJA também. Dessa vez, por ser novo demais e apresentar o mesmo comportamento que apresentava no cenário anterior. Sendo assim, concluímos que esse educando não se encaixa mais no ensino fundamental e médio normal, entretanto, também não se encaixa na EJA. Aonde é o lugar desse jovem?

Acreditamos que esses questionamentos evidenciam ainda mais a necessidade de novas reflexões e discussões acerca da escola regular e também da Educação de Jovens e adultos.

O fenômeno da juvenilização vem e traz a necessidade de repensarmos no modo como os professores estão atuando com os adolescentes, do mesmo modo, traz também, a necessidade de repensarmos na educação que o Estado está oferecendo, desde os conteúdos, até a sua organização. Será que aquilo que se busca é o que está sendo ofertado? Será que aquilo que está sendo ofertado e o modo de oferta ainda se encaixa no contexto atual ou é preciso repensar em uma nova escola, frente ao surgimento do novo perfil de aluno?

\section{REFERÊNCIAS}

ANDRADE, Eliane Ribeiro. Os jovens da EJA e a EJA dos jovens. In: OLIVEIRA, Inês Barbosa; PAIVA, Jane. Educação de Jovens e Adultos. Rio de Janeiro: DP\& A, 2004.

BRASIL. Ministério da Educação. Lei de Diretrizes e Bases da Educação Nacional. Lei n. 9.394/96. Disponível em:http://www.planalto.gov.br/ccivil_03/Leis/L9394.htm. Acesso em: 10 Jul 2010.

BRASIL. Conselho Nacional de Educação. Câmara de Educação Básica. Carlos Roberto Jamil Cury (relator). Parecer CEB11/2000 - Diretrizes curriculares nacionais para a educação de jovens e adultos. In: SOARES, Leôncio. Educação de jovens e adultos. Rio de Janeiro: DP\&A, 2002b. p. 25-133.

BRUNEL, Carmen. Jovens cada vez mais jovens na educação de jovens e adultos. Porto Alegre: Medicação: 2004.

FARIAS, A. M. A subalternidade e emancipação nas politicas educacionais brasileiras de EJA implementadas pós década de 1940. Disponível em: $<$ http://www.portalanpedsul.com.br/admin/uploads/2012/Educacao_de_Pessoas_Jovens _e_Adultas/Trabalho/06_51_12_2761-6622-1-PB.pdf>. Acesso em: 05 mai. 2016. 


\section{SEMINÁRIO DE PESQUISA EM CIÊNCIAS HUMANAS - SEPECH \\ Humanidades, Estado e desafios didático-científicos \\ Londrina, 27 a 29 de julho de 2016}

FERNANDES, Elisângela. Porque os jovens de 15 a 17 anos estão na EJA. Disponível em:

$<\quad$ http://revistaescola.abril.com.br/politicas-publicas/jovens-15-17-anos-estao-eja639052.shtml>. Acesso em: 16 mai. 2016.

GIOVANETTI. Maria Amélia. A formação de educadores da EJA: o legado da educação popular. In: SOARES, Leôncio. GIOVANETTI, Maria Amélia. GOMES, Lima Lino. Diálogos na educação de jovens e adultos. Belo Horizonte, Autêntica, 2005.

OLIVEIRA, I. B. de; PAIVA, J. (org.). Educação de Jovens e Adultos. Rio de Janeiro: DP\&A, 2004. p. 43-54. Disponível em: <http://www.manancialvox.com/diversos/Osjovens-da-EJA-e-a-EJA-dos-jovens.txt>. Acesso em: 16 mai. 2016.

OLIVEIRA, M. K. de. Sobre diferenças individuais e diferenças culturais: o lugar da abordagem histórico-cultural. In: AQUINO, J.G. (org.) Erro e fracasso na escola: alternativas teóricas e práticas. São Paulo: Summus, 1997.

PEREIRA, E. D. Adolescência: um jeito de fazer. Revista da UFG, v.6, n ${ }^{\mathrm{o}}$ 1, jun 2004. Disponível em: <http://www.proec.ufg.br/revista_ufg/juventude/adoles.html $>$. Acesso em: 22 set. 2015.

PORTAL ODM. Brasil ainda tem 13 milhões de analfabetos com 15 anos ou mais. Disponível em: <http://www.portalodm.com.br/noticia/1302/brasil-ainda-tem-13milhoes-de-analfabetos-com-15-anos-ou-mais>. Acesso em: 16 mai. 2016.

RIBEIRO, Vera Maria Masagão. Educação de Jovens e Adultos: proposta curricular para o $1^{\circ}$ segmento do ensino fundamental. São Paulo/Brasília, 1997: MEC - Ministério da Educação e Ação

RUMERT, Sônia Maria. A educação de jovens e adultos trabalhadores brasileiros no século XXI. O "novo" que reitera antiga destituição de direitos. Sisifo/revista de ciências da educação, n. 02, jan/abr 2008.

UOL. Brasil ainda tem 13 milhões de analfabetos com 15 anos ou mais. Disponível em: http://educacao.uol.com.br/noticias/2014/09/18/brasil-ainda-tem-13-milhoes-deanalfabetos-com-15-anos-ou-mais.htm>. Acesso em: 16 mai. 2016.

UNICEF. 10 desafios para o Ensino Médio no Brasil. Para garantir o direito de aprender de adolescentes de 15 a 17 anos. Brasília, UNICEF, 2014. Disponível em: http://www.unicef.org/brazil/pt/10desafios_ensino_medio.pdf. Acesso em: 16 de Maio de 2016. 